\title{
REFLEXÕES SOBRE A RELAÇÃO PSICOTERAPÊUTICA: DIÁLOGOS COM MERLEAU-PONTY
}

\author{
Thinking on Psychotherapeutic Relationship: Dialogues with Merleau-Ponty \\ Reflexiones sobre la Relación Psicoterapéutica: Diálogos con Merleau-Ponty
}

JOANNELIESE DE LUCAS FREITAS

\begin{abstract}
Resumo: O presente artigo tem como objetivo discutir como podemos entender a relação terapêutica a partir de um diálogo com a compreensão do outro em Merleau-Ponty. Tendo como pressuposto a Gestalt-terapia para a compreensão das relações entre psicoterapeuta e cliente, problematiza-se as relações humanas e a comunicação no contexto psicoterapêutico. A partir do paradoxo eu-outro e a partir da compreensão da corporeidade como parte do campo homem-mundo, coloca-se em questão o diálogo e o encontro. Defende-se a tese de que em uma relação terapêutica é preciso que psicoterapeuta e cliente se encontrem em suas diferenças. Sendo assim, a postura terapêutica implica em uma busca incessante para a compreensão e a disponibilidade ao outro para que ele, cliente, possa ver a si mesmo por intermédio da diferenças que emergem no campo terapeuta-cliente. O psicoterapeuta deve atuar no campo da relação e, portanto, servir de abertura entre o cliente e o mundo em um esforço para alcançar a vivência experienciada por seu cliente.
\end{abstract}

Palavras-chave: Relação Psicoterapêutica; Diálogo; Campo; Merleau-Ponty; Gestalt-terapia.

\begin{abstract}
The present article has the objective of examining how we can understand the therapeutic relationship from the dialogue with the Merleau-Ponty's concept of other. The human interaction and communication in the psychotherapeutic contexts are discussed utilizing the understanding of psychotherapeutic relationship in Gestalt-therapy. The subject of dialog and the encounter are raised from the paradox I-other as well as the understanding of corporeity as part of the man-world field. The article presents the idea that in a therapeutic relationship both psychotherapist and client must encounter with each other in their differences. That being said, the therapeutic stance implies a non-stop search for the comprehension and the availability of the other so that the client may come to grasp himself through the differences that emerges at the therapist-client field. The psychotherapist must act on the field of the relationship and, therefore, operate as an opening between the client and the world as an effort to reach the lived-experience of his client.
\end{abstract}

Keywords: Psychotherapeutic Relationship; Dialog; Field; Merleau-Ponty; Gestalt-therapy.

Resumen: El objetivo del presente artículo es discutir como podemos entender la relación terapéutica a partir del diálogo con el otro en Merleau-Ponty. Teniendo en cuenta que la comprensión de la relación entre psicoterapeuta y cliente en la terapia gestáltica, plantea la cuestión de las relaciones humanas y la comunicación en el contexto terapéutico. A partir de la paradoja yo/ otro y de la comprensión de la corporeidad como parte del campo del hombre/mundo, se cuestiona el diálogo y el encuentro. Se defiende la tesis que en una relación terapéutica se precisa que el psicoterapeuta y el cliente se encuentren en sus diferencias. Siendo así, la postura terapéutica implica en una búsqueda incesante de la comprensión y de la disponibilidad al otro, para que este, cliente, pueda verse a sí mismo a través de las diferencias que surgen en el campo terapeuta/cliente. El psicoterapeuta debe actuar en el campo de la relación y, por lo tanto, servir para la abertura entre el cliente y el mundo, en un esfuerzo de alcanzar la vivencia experimentada de su cliente.

Palabras-clave: Relación Psicoterapéutica; Diálogo; Campo; Merleau-Ponty; Terapia Gestáltica.

A psicoterapia se constitui como um processo que, conforme a perspectiva teórica adotada pelo psicoterapeuta, apresenta diversos e variados objetivos, muitas vezes divergentes entre si. Contudo, independente de seus objetivos, em sua forma, a psicoterapia implica sempre em uma relação. Cada perspectiva teórica em psicologia apresenta postulados próprios e diferenciados a respeito de qual tipo de relação, de vínculo, deve ser construído entre terapeuta e cliente, assim como a forma pela qual este vínculo deve ser estabelecido para que o processo terapêutico se faça. Ou seja, a cada compreensão sobre $o$ que é o vínculo psicoterapeuta-paciente ou sobre o que é a relação terapêutica, há uma compreensão sobre o como se deve ser estabelecida esta relação. No presente artigo, pretendemos discutir uma das possíveis formas de compreender o vínculo entre psicoterapeuta e cliente, a partir da reflexão de alguns aspectos da psicoterapia dialógica em Gestalt-terapia.

Entendemos que o vínculo terapêutico não se constitui apenas como conseqüência de uma série de contingências ou aplicações técnicas, mas, sobretudo e, principalmente, anterior a qualquer especificidade técnica, 
o vínculo entre terapeuta e cliente se constitui como humano. Como dissemos acima, a perspectiva teórica que adotamos para a compreensão do processo terapêutico é da Gestalt-Terapia (Perls, Hefferline \& Goodman, 1997). Entretanto, não nos limitamos à compreensão desta teoria. Utilizamo-nos também da filosofia fenomenológica de Merleau-Ponty (1969/2002) sobre a relação dialógica e a constituição das possibilidades de relação com o outro e com a diferença. Trazer à tona a compreensão da relação com a alteridade conforme pensada por Merleau-Ponty justifica-se pela qualidade do diálogo possível entre a compreensão de homem que encontramos na obra deste autor e a visão de homem em várias teorias humanistas, especificamente a Gestalt-terapia. A apreensão do método fenomenológico por este autor e suas concepções sobre a existência se aproximam muito da perspectiva de homem proposta pela Gestalt-terapia.

Na prática da clínica psicológica, seja entre psicoterapeutas experientes, seja entre os iniciantes, observamos que a construção do vínculo se constitui como um dos maiores desafios que se nos apresenta. Teorias e técnicas das mais variadas são ensinadas nos cursos de graduação em psicologia para que o profissional possa estabelecer uma relação que seja considerada satisfatória para o andamento de um processo terapêutico. O problema é justamente estabelecer quais são os parâmetros desta relação e o que podemos considerar como satisfatório dentro de cada paradigma ontológico e epistemológico. Nas ciências humanas, faz-se necessário assumir um paradigma que diga respeito a quem é o homem e como este se relaciona com o mundo que o cerca. Em perspectivas teóricas de inspiração ou influência fenomenológica, não podemos nos furtar de assumir a reflexão imposta pela fenomenologia à Psicologia como possibilitadora de uma nova postura para o questionamento dos fenômenos psicológicos: o de se interrogar sobre as experiências vividas e, portanto, sobre as relações sujeito-mundo de uma forma não dicotomizada (Bruns, 2003). Tarefa complexa, especialmente se observarmos que nas décadas de 40 e 50 do século XX, quando houve o "boom" das teorias psicológicas americanas e européias que sofreram influência da filosofia de Husserl, direta ou indiretamente, a linguagem da psicologia ainda direcionava (direciona?) o nosso pensamento para uma compreensão e percepção de mundo dicotomizada entre sujeito e objeto, entre mundo interno e mundo externo. Um exemplo claro deste momento de mudança de paradigmas é o próprio livro Gestalt-terapia de Fritz Perls, Paul Goodman e Ralph Hefferline (1997), considerado por muitos gestalt-terapeutas como a "bíblia da gestalt”. Apesar de apresentar um novo paradigma para a compreensão do homem e do desenvolvimento em psicologia, não consegue se livrar de uma linguagem "viciada" da psicologia dualista e apresenta conceitos que perpetuam uma visão de mundo dicotomizada, apesar da busca por uma compreensão mais dialética, tal como podemos perceber no conceito de "bom" e "mau" contato.
Entendemos que homem e mundo não podem ser compreendidos separadamente, ou melhor, não podem ser compreendidos fora de um campo fenomenal, já que compreendê-los fora do campo seria ainda compreendê-los dicotomicamente. Buscar um paradigma que compreenda e atue frente ao homem fora de uma visão dicotômica não significa descartar sua ambiguidade no mundo, não significa, pois, retornar a uma concepção monista de mundo ou de homem, mas compreendê-lo em suas tensões ambíguas próprias à compreensão do homem enquanto campo. A partir desta perspectiva, o vínculo terapêutico não pode ser compreendido fora das relações de campo e fora do mundo vivido, o que nos leva às seguintes questões: o que faz com que seja possível o estabelecimento de uma relação? De que natureza é esta relação? Como é possível a comunicação a partir desta relação? Como podemos perceber a expressão do outro, sua percepção de mundo, ou melhor, seu mundo? Há a possibilidade de percepção de seu mundo (do outro) como distinto? Ou, em termos da clínica psicológica: é possível compreender o mundo deste outro que se nos apresenta como clientes? Se sim, como se dá esta compreensão? De que natureza é esta compreensão? Deixemos claro que não pretendemos responder a todas estas questões, nem tampouco apresentar uma proposta de compreensão que se apresente como forma definitiva para o trabalho clínico, senão problematizá-las frente a uma concepção naturalista onde se considera que o psicoterapeuta tem a capacidade e o poder de atingir e interferir no mundo e na existência do outro de forma neutra, controlada e objetiva.

Compreender o mundo do cliente é compreender a sua verdade e a sua ambiguidade enquanto ser-no-mundo (Sapienza, 2004). É compreender o terapeuta também a partir desta mesma ambiguidade. Assim como o pesquisador ou o filósofo que tentam compreender o mundo, o psicoterapeuta é um ser-no-mundo e não alguém dotado de uma verdade, resposta ou saída para o sofrimento do outro. Assumir a busca de compreensão do mundo do cliente é também assumir a (im)possibilidade de alcançar a percepção do outro a partir da experiência vivida e não apenas a partir do que a racionalidade nos apresenta. E, ao contrário do que muitas vezes acreditamos, não basta "estar" na relação ou "vivê-la" para que possamos verdadeiramente apreender o outro da forma tal como se apresenta em sua vivência. E é justamente este ponto que pretendemos discutir no presente artigo para problematizar as questões antes colocadas: a da ambiguidade na qual se encontra o terapeuta entre a existência, o encontro vivido, pré-reflexivo e a reflexão coerente que implicam em uma atitude ética e compromissada com a pessoa que busca a psicoterapia.

Em Gestalt-terapia, compreendemos a relação e, por consequência, a relação terapêutica, como a referência de todo e qualquer trabalho clínico e ainda de toda e qualquer possibilidade de transformação, inclusive aquelas implicadas no desenvolvimento e na existência cotidiana (Ribeiro, 1997; Perls, Hefferline \& Goodman, 1997). 
Sendo compreendida como uma dialética sem síntese, é a relação dialógica que possibilita que nos façamos sujeitos, e apenas permitindo ao outro ser sujeito, podemos também sê-lo (Hycner, 1995).

A existência de uma subjetividade requer um engajamento em uma relação onde se possa reconhecer, ao mesmo tempo, as possibilidades de minha existência e da existência de um outro eu, uma possibilidade de um outro sujeito fora de mim mesmo, estabelecendo assim, um espaço da diferença, uma vivência concreta do campo que somos. E ainda: reconhecer a si mesmo como alguém que só pode existir quando se movimenta para fora de seus limites, sejam eles corporais, sociais ou mesmo individuais, rompendo com o que há de habitual para se dirigir ao conflito inerente ao movimento da existência. É neste encontro com a alteridade, que se realizam as possibilidades de si mesmo, pois é o tu, ou o "outro eu" que o delimita, que marca suas fronteiras com o mundo. Antes destas experiências com a alteridade, não é possível a experiência consigo mesmo, o que vemos confirmado pelas mais variadas teorias psicológicas, especialmente no que tange à psicologia do desenvolvimento (Piaget, 1975; Vygotsky, 1991; Freud, 1932/1996; Spitz, 2000; Bowlby, 1990; Valsiner, 1989). Frente às presentes colocações e pensando na relação entre o psicoterapeuta e seu cliente, o desafio se torna compreender como o psicoterapeuta, com sua presença e fala, com sua expressão e modos de ser um mundo para o outro, pode romper com as fronteiras do outro para permitir sua produção em terapia. É assumir uma postura específica frente ao desenvolvimento humano.

A relação terapêutica se constitui como apenas uma das várias relações cotidianas que fazem parte da existência e deve ser entendida como tal. Sabemos que não há a possibilidade de existirmos sem a relação com um mundo (dos objetos e social), porém, segundo MerleauPonty (1945/1994), o sujeito já nasce consagrado a si e ao mundo porque carrega um corpo. Dessa forma, não podemos nos destacar daquilo que há de mais material em nós mesmos, que nos constitui enquanto iguais: o corpo. "Sou tudo aquilo que vejo, sou um campo intersubjetivo, não a despeito de meu corpo e de minha situação histórica, mas ao contrário sendo esse corpo e essa situação e através deles todo o resto" (Merleau-Ponty, 1945/1994, p. 606). Percebemos aqui um elemento novo e fundamental para a compreensão das relações que é a forma pela qual se compreende o corpo como campo. E, ultrapassando a questão da compreensão, percebemos uma opção ontológica radical pela inclusão do corpo como ponto e alicerce fundamental da existência.

O homem é, então, aquele que se constitui em mundo prenhe de significações vividas. As relações que estabelecemos no mundo são formas de nos aproximarmos não apenas do mundo assim como a única maneira de nos aproximarmos de nossa vivência. Paralelamente, aprendemos com Merleau-Ponty (1969/2002) que o outro, é um "outro eu mesmo", isto é, há um eu que é outro, me desti- tuindo de minha posição central, mas que, todavia, não está diante de mim, pois o que está diante, à frente é sempre um ob-jeto, do latim, ob-jectum. $O b$ em latim significa diante, em frente de, e jactea, jogado à frente (Dicionário Português-Latim, 1989). Ou ainda, segundo o Dicionário Etimológico da Língua Portuguesa (Cunha, 1997), observamos a primeira derivação da palavra objeto como algo que se interpõe à minha frente. Assim, sob o ponto de vista merleau-pontiano, podemos compreender sua afirmação de que o outro jamais se apresenta de frente, como uma coisa, ele é esta réplica, este duplo errante de mim mesmo (Merleau-Ponty, 1969/2002). Segundo o autor, o corpo do outro sim, está diante de mim, mas não sua existência. O mistério do outro não é, pois, senão o mistério de mim mesmo e é justamente porque sou uma totalidade, um campo, que sou capaz de colocar o outro no mundo e me ver limitado por ele, e não ao contrário. Como em qualquer outra relação, assim é também na relação terapêutica: nunca podemos perceber, nem tampouco apreender totalmente o outro que se apresenta nesta relação, isto é, o cliente da psicoterapia. Nunca podemos apreender todos seus meandros, suas intenções, suas dores, ele é sempre um mistério, porém, sempre o mistério de mim mesmo, o mistério da própria humanidade do terapeuta. Não é apenas pela abstinência ou uma neutralidade aparente que o terapeuta se torna um mistério para o seu cliente, mas o é como existência. Não é apenas como um conjunto de sintomas que carecem de sentido que o cliente se constitui como uma pergunta para o psicoterapeuta, mas pela sua existência. A não ser que "eu" (psicoterapeuta) o tome como um objeto e tome a mim mesmo como centro da relação. Quando o psicoterapeuta compreende seu cliente como um objeto para o "eu penso" ele (psicoterapeuta), se torna o centro da relação reafirmada pelo poder de um $s a$ ber, de uma verdade oculta que saberá desvelar, definindo e escrutinando "o campo do outro que se apresenta". Mas, inversamente, para que entre esse mistério que sou eu e este mistério que é o outro aconteça uma relação e, para que o diálogo se estabeleça, é preciso que nossos campos se multipliquem, pois um campo não exclui nem tampouco está contido no outro. O que faz com que, na verdade, não seja o campo do outro (ou simplesmente o outro, o cliente) que se constitua como trabalho, mas o campo terapeutacliente, o campo multiplicado do encontro.

Assim como afirma ser para o corpo, Merleau-Ponty (1969/2002) afirma que o campo é a abertura pela qual sou exposto ao mundo. Só quando o outro está em meu campo é que posso percebê-lo como outro, pois ele não está nas coisas, não está em mim e nem mesmo em seu corpo, mas em meu campo, não como um eu "em si mesmo", mas como um outro eu, mistério de mim. O outro se torna mistério de mim por me fazer entrar em contato e, nesse contato, nessa relação, seu desenrolar tem o poder de lançar-me a uma significação inédita que nem ele, nem eu possuíamos antes deste encontro. Destarte, meu campo se revela como fonte inesgotável de ser, não ape- 
nas de ser para mim, mas também de ser para outrem. E é assim que encontramos o outro, da mesma forma que encontramos nossa corporeidade: como ato expressivo. Psicoterapeuta e cliente se encontram, portanto, como expressão de um mesmo campo.

O diálogo humano segundo Merleau-Ponty (1969/2002), e, consequentemente o diálogo terapêutico, por sua natureza humana, se procede, então, em dois níveis: o da corporeidade, como uma tese subentendida por todas nossas experiências, o fundo do qual emerge nossa subjetividade, e o da fala, gesto que nos permite tocar à distância a própria linguagem, tese subentendida de todo significado. $\mathrm{O}$ corpo é, portanto, fundo da expressão, assim como a linguagem, gesto corpóreo, enquanto se constitui como uma linguagem que fala a partir de si e não como linguagem já falada (Merleau-Ponty, 1945/1994, Amatuzzi, 1989).

Se é por intermédio do corpo que podemos ter condição de se dar um mundo, ambígua e expressivamente, podemos refletir sobre as relações entre a corporeidade e a fronteira de contato, conceito fundamental para a gestalt-terapia.

Uma imagem particularmente esclarecedora pode ser aquela provocada pela analogia entre a pele e a fronteira de contato. Esta imagem faz criar raízes no pensamento que postula ser justamente no corpo onde encontramos o nó entre o ser-em-si e o ser-para-si, o ser e o mundo, a linguagem e a temporalidade (Freitas, 2005; MerleauPonty, 1945/2004).

A maneira como a psicologia tratou durante muito tempo a corporeidade parece-nos reducionista, visto que esta foi apenas entendida como organismo e não como lugar possível de apreensão de sentido, assim compreendido quando o percebemos como o lugar mesmo das nossas experiências ou daquilo que Merleau-Ponty (1945/2004) chama de vivido. Apenas na psicologia clínica, com autores como Perls, Hefferline e Goodman (1997) e Reich (2001), pudemos divisar possibilidades de transformação na relação do homem com o corpo. Sendo o corpo entendido como o nó existencial do sujeito, é nele que experenciamos as relações que o significam, é sendo esta corporeidade que experienciamos pela primeira vez o contato. E o que é a experiência clínica senão a possibilidade de contato genuíno de uma presença para o outro?

O contato é possibilitado durante o encontro de várias maneiras: um olhar, um gesto, um toque, um suspiro, a percepção das tensões musculares, da postura, do silêncio, da aceitação. Se optarmos por uma análise da fronteira de contato, de como esta pessoa se aproxima das coisas, situações e pessoas, optamos por nos colocarmos enquanto terapeutas frente às maneiras particulares de nossos clientes se relacionarem com o mundo, suas expectativas e dificuldades e seus pontos de autoproteção ou resistências. Aí estão as grandes estruturas estudadas por um gestaltterapeuta: o fluxo existente entre uma pessoa e seu mundo, o fluxo da intersubjetividade e não mais uma perspectiva individualista e personalista, como muitas vezes testemunhamos acontecer. E é justamente a sua temporalidade atualizada pela corporeidade que preenche estas estruturas de sentido.

Sendo contato através de presença, percebe-se que há, portanto, uma universalidade no sentir que nos permite comunicar. Nesta noção de comunicação a idéia de concordância se expressa como sendo de outra ordem, diferente da ordem do senso comum: "Concordância não exige que cheguemos todos à mesma idéia pelo mesmo caminho, (...) mas que toda experiência comporte pontos de abertura a todas idéias e que estas tenham uma possibilidade de configuração em meu campo"(Merleau-Ponty, 1969/2002, p. 177). Em um sentido ordinário, não há como concordar com meu cliente. Não há como espelhar em mim sua experiência de mundo. Não há como explicar ou prover um sentido teórico ou filosófico à sua dor. Não preciso compreender e não posso compreender exatamente a dor da ferida do meu cliente, este outro que se apresenta em meu campo, mas posso compreender, por intermédio de meu campo, enquanto abertura e enquanto fonte inesgotável de ser, posso compreender, então, "Como a mordida do mundo lhe fere” (Merleau-Ponty, 1969/2002, p. 177), uma vez que o outro está exposto ao/no mundo, tal como eu, já que é corporeidade, tal como eu sou.

Como psicoterapeutas, atuamos exatamente nesta área intermediária entre o subjetivo e o objetivo, se constituindo, portanto, dentro de minha concepção, como uma atuação no campo. É este o lugar onde se mostram as relações e o homem, onde podemos nos perceber diferentes de nossos clientes, porém intimamente ligados a eles através de nossos corpos ou, ainda, de nossa corporeidade. É, pois, este o lugar do corpo segundo Merleau-Ponty que, por implicação, também é o lugar do corpo na relação psicoterapêutica: um lugar originário, o lugar do vivido, o lugar que toca e estabelece a fronteira com o outro, o lugar do "nós" que se frutifica naquela experiência cotidiana que nos habituamos a chamar de "eu”. É assim em qualquer relação e também no processo terapêutico. Há o estabelecimento de uma relação, também material, mas que é experienciada pela pessoa, que aqui nos ocupamos como cliente, a partir de sua finitude, representada pela morte, pelo seu corpo e pela impossibilidade do terapeuta estar para sempre com ele. É importante notar que estamos marcados pelo outro e pela ambiguidade de nos tornamos algo que também se separa deste outro. Para que ocorra o encontro eu-tu nos utilizamos de variadas formas de expressão, especialmente da fala, este gesto que se constitui como linguagem. A fala pode ser pensada como uma corporeidade anônima e que, "por um movimento, a princípio violento, pode ultrapassar toda a significação para atingir o sentido" (Merleau-Ponty, 1969/2002, p. 176). É preciso que a própria fala se torne fundo para que o sentido emerja, o sentido deste outro que se desvela como uma nova verdade para mim. É preciso que eu, enquanto terapeuta, fique durante certo momento surpreso, desorientado e que, para que possamos dialogar, nos encontremos 
não no que temos de semelhante, mas no que temos de diferente. É preciso que a diferença torne-se sentido para mim. Sendo assim, a postura terapêutica implica em uma busca incessante para a compreensão e a disponibilidade ao outro, para que ele, cliente, possa ver a si mesmo por intermédio da minha (ou nossas) diferenças, mas, como conseguir isso? Percebendo a sua diferença no meu próprio campo, como sentido para mim mesmo. Tal postura é completamente diferente daquela de um terapeuta que reproduz a sua fala e a sua intervenção como um cientista certo de seus conceitos e de si mesmo, pois trilhar os meandros de mim mesmo que não conheço, pode, para muitos, não parecer seguro. E de fato não é.

A ciência exata fala das coisas, não supõe um outro como interlocutor, mas o próprio conhecimento como interlocutor. Deseja conduzir pela mão este outro-cliente do ponto que este sabe ao ponto no qual o terapeuta sabe que ele (cliente) deve chegar, ignorando o fato de que a transformação, a possibilidade de se alcançar um novo sentido de si mesmo habita fora de todas as definições. Enfim, não se trata de lançar o outro em direção ao que sei e que ele ainda não compreendeu, nem tampouco de orientar-me, eu mesmo, em direção ao que vou compreender. O que mascara a fala e a intervenção diretiva de um terapeuta é tomar a fala pelo enunciado e esquecer o que há de tácito, de não formulado ou tematizado que habita o campo e a corporeidade. Trata-se de um diálogo, de uma construção conjunta onde não há mestres nem guias, mas encontro, desde que estejamos disponíveis para trilhar caminhos onde essa fala conquistadora, esse gesto corporal, rasgando meu campo em busca de novos sentidos, possa brotar. O terapeuta deve servir de campo de abertura entre o cliente e o mundo, entre o cliente e si mesmo, em um retorno às nossas estruturas ou configurações antes aqui defendidas: à própria possibilidade de nos dispormos aos acontecimentos e ao fluxo do vivido. A postura deve ser de aceitação e de disponibilidade de sentidos. Deve ser uma postura que ofereça uma possibilidade de mundo onde o outro possa se abrir a um novo sentido nunca previamente conhecido. É tocar esse outro à distância, para que ele possa se desvelar como sua própria verdade. E, por fim, uma postura responsável para que possamos sustentar e permitir a emersão desta subjetividade, deste self, com suas qualidades e defeitos, potencialidades e dificuldades, para que essa pessoa possa ser aceita e se aceitar, estando aberta às mudanças possibilitadas pelo fluxo do vivido. Não eliminando, mas integrando e possibilitando sentido às vivências. E, por último, o cuidado ético de não prometer aquilo que não se pode fazer ou o que ainda não se sabe como será trilhado.

\section{Referências}

Amatuzzi, M. M. (1989). O resgate da fala autêntica. São Paulo: Papirus.

Bowlby, J. (1990). Apego. São Paulo: Martins Fontes.
Bruns, M. A. T. (2003). A redução fenomenológica em Husserl e a possibilidade de superar impasses da dicotomia subjetividade-objetividade. Em M. A. T. Bruns \& A. F. Holanda (Orgs.), Psicologia e fenomenologia. São Paulo: Alínea.

Cunha, A. G. (1997). Dicionário Etimológico da Língua Portuguesa (2. ed.). Rio de Janeiro: Nova Fronteira.

Dicionário Português latim (1989). Em Coleção Dicionários Acadêmicos. Cidade do Porto: Porto Editora.

Freitas, J. L. (2005). Ruptura e sentido na experiência de adoecimento e morte. Tese de Doutorado em Psicologia, Brasília, Universidade de Brasília.

Freud, S. (1996). Conferência XXXI. Em Edição Standard das Obras Completas de Sigmund Freud (Vol. 22) Rio de Janeiro: Imago. (Originalmente publicado em 1932).

Hycner, R. (1995). De pessoa a pessoa. São Paulo: Summus.

Merleau-Ponty, M. (1994). A fenomenologia da percepção. São Paulo: Martins Fontes. (Originalmente publicado em 1945).

Merleau-Ponty, M. (2002). A prosa do mundo. São Paulo: Cosac \& Naify. (Originalmente publicado em 1969).

Perls, F. S., Hefferline, F. R., \& Goodman, P. (1997). Gestaltterapia. São Paulo: Summus.

Piaget, J. (1975). O Nascimento da Inteligência na Criança. Rio de Janeiro: Zahar Editores.

Pompéia, J. A., \& Sapienza, B. T. (2004). Uma caracterização da psicoterapia. Em J. A. Pompéia \& B. T. Sapienza, Na presença do sentido. São Paulo: EDUC/Paulus.

Reich, W. (2001). Análise do caráter. São Paulo: Martins Fontes

Spitz, R. (2000). O primeiro ano de vida. São Paulo: Martins Fontes.

Valsiner, J. (1989). Human development and culture - the social nature of personality and its study. EUA: Lexington Books.

Vygotsky, L. S. (1991). Pensamento e linguagem (3a. ed.). São Paulo: Martins Fontes.

Ribeiro, W. F. R. (2008) Human Interactions: Can we improve them? New York: Gestalt Journal Press.

Joanneliese de Lucas Freitas - Doutora em Psicologia pela Universidade de Brasília e Professor-Adjunto da Universidade Federal do Paraná. Endereço para correspondência: Departamento de Psicologia, Universidade Federal do Paraná, Praça Santos Andrade, 50 - Sala 215 (Ala Alfredo Buffren). CEP: 80060.240 - Curitiba / PR. Email: joanne@ufpr.br

Recebido em 18.06.09

Aceito em 30.08.09 